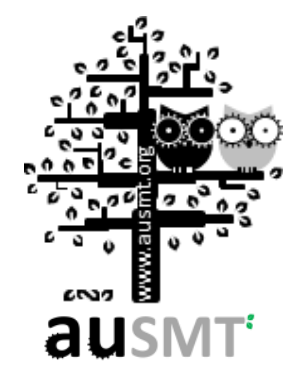

\title{
The Effect of Heating Conditions on Convective Boiling Characteristics of Methanol/Water Mixtures in Microchannels at Low Reynolds Number
}

\author{
Chen-li Sun'1, ${ }^{*}$, Ming-Hsien Shi², and Chuan-Yu Wang3 \\ ${ }^{1}$ Department of Mechanical Engineering, National Taiwan University, Taiwan \\ ${ }^{2}$ China Steel Corporation, Taiwan \\ ${ }^{3}$ Hon Hai Precision Industry Corporation, Taiwan \\ (Received 30 October 2015; Accepted 1 March 2016; Published on line 1 June 2016) \\ *Corresponding author: clsun@ntu.edu.tw \\ DOI: $10.5875 /$ ausmt.v6i2.1053
}

\begin{abstract}
In this study, flow boiling of methanol/water mixtures in a microchannel was investigated under the conditions of constant heat flux and constant wall temperature at low Reynolds number. The heating condition had a profound effect on regime maps of flow boiling in a microchannel. Under isothermal conditions, nucleation occurred when the wall was slightly superheated and annular flow was quickly established. The composition of the mixture played a minor role under isothermal conditions. On the other hand, bubbles could possibly emerge at subcooled temperatures under the constant heat flux condition, and the rupture of the liquid film in the annular flow lead to a unique phenomenon - sheet breakup. Because of the large deviation between the bubble point and dew point, sheet breakup spanned a very high superheat for mixtures with mole fractions of 0.07 and 0.3 . As a result, the superheat associated with the transition to mist flow was elevated, and the critical heat flux (CHF) was increased. In contrast, annular flow barely persisted for mixtures with a mole fraction larger than 0.7 . The low surface tension made it difficult to maintain the vapor-liquid interface and nucleation directly burst into sheet breakup or mist flow.
\end{abstract}

Keywords: flow boiling, microchannels, methanol/water mixtures, heating condition, regime map, heat transfer

\section{Introduction}

Technologies for semiconductor microfabrication were used to reduce the size of the devices in order to develop MEMS (MicroElectroMechanical Systems) The miniaturization provided several benefits, such as better portability, minimum volume, lower power consumption, and faster response time. Recent research had shown that the boiling process in microstructures could be used in ink ejection for printhead [1], micropump actuation [2], fuel processing in a $\mu$ DMFC (Micro Direct Methanol Fuel Cell) [3], and electronic cooling [4, 5].

The characteristics of two-phase forced convective flow in micro devices have attracted considerable attention in the past decade. Zhang et al. [6] successfully fabricated microchannels on silicon wafer with ionimplanted resistors to conduct flow boiling experiments. In their study, deionized water was used as the working fluid and the hydraulic diameters of microchannels were $31 \mu \mathrm{m}$ and $58 \mu \mathrm{m}$. The results showed that pressure increased dramatically after the onset of boiling, and boiling occurred without excessive superheating. Later, Zhang et al. [7] broadened the hydraulic diameter range of the tested microchannels $(27 \mu \mathrm{m}$ to $171 \mu \mathrm{m})$, and purposely varied the surface roughness of the microchannels to examine its effects on the boiling mechanism. Two bubble formation mechanisms were identified: typical nucleation and eruption boiling. For diameters larger than $100 \mu \mathrm{m}$, typical nucleation was observed. As the diameter fell below $50 \mu \mathrm{m}$, a fast oscillating interface erupted and extended in the longitudinal direction to produce a two-phase mist downstream. Jiang et al. [8] presented experimental results of forced convective boiling in triangular microchannels with hydraulic diameters of $26 \mu \mathrm{m}$ and 53 $\mu \mathrm{m}$. One distinct characteristic they observed was that there was no boiling plateau in the boiling curves, 
indicating the temperature slope decreased with increasing input power. Qu and Mudawar [4] further explored the heat transfer characteristics of flow boiling in two-phase microchannel heat sinks and found a similar trend. As vapor content increased, the heat transfer coefficient decreased. Qu and Mudawar [4] pointed out that the deterioration of heat transfer was ascribed to the droplet entrainment and deposition within the annular flow region. To address the discrepancy of flow boiling heat transfer in microchannels and macrochannels, various investigations had proposed new correlations and good agreement was achieved [4, 9-11]. Yet no report was found to validate their applicability to flow boiling in microchannels with hydraulic diameters smaller than 300 $\mu \mathrm{m}$ at a Reynolds number lower than 12.

At the macroscale, mixtures such as ethylene glycol/water or refrigerants are commonly used as working fluids in phase-change processes. Despite their broad applications in industry, few studies have explored the role of the composition in microscale convective boiling heat transfer. Because the more volatile component prefers to evaporate at the vapor-liquid interface, properties varied in the streamwise direction and nucleation was suppressed. As a result, the flow boiling characteristics of binary mixtures could be very different from those of pure fluids. The pioneering work by Peng et al. [12] investigated the flow boiling heat transfer characteristics of methanol/water mixtures in microchannels. Machined from stainless steel substrates, microchannels with hydraulic diameters varying from 133 $\mu \mathrm{m}$ to $343 \mu \mathrm{m}$ were used to explore the effects of channel configuration, flow velocity, and concentration on microscale flow boiling. Peng et al. [12] found that there is an optimum concentration to achieve maximum heat transfer. Moreover, concentration showed stronger influences on heat transfer coefficients during the initial stage of flow boiling, but became less important when fully nucleate boiling regime was reached. Adding small

Chen-li Sun received her Ph.D. from the University of California at Berkeley in 2002 in Mechanical Engineering. In 2002-03, Dr. Sun was a postdoctoral researcher for Prof. Al P. Pisano in the Berkeley Sensor and Actuator Center (BSAC). From 2003 to 2011, Dr. Sun was on the faculty of the National Taiwan University of Science and Technology, before joining the Department of Mechanical Engineering at National Taiwan University. Dr. Sun received the Distinguished Young Scholar Award from the Society of Theoretical and Applied Mechanics in 2014 and the Ta-You Wu Memorial Award from National Science Council in 2012. Her research interests focus on near-interface microscale transport phenomena, phase-change heat transfer and energy systems. Specifically, she is interested in designing smart systems in thermofluidics and Energy.

Ming-Hsien Shi received his M.S. in Mechanical Engineering from National Taiwan University of Science and Technology in 2007. He joined the China Steel Corporation in 2007 and is currently an engineer in the Department of Continuous Casting. His research interests focus on the phase-change process of cooling water to the mould or within the strand.

Chuan-Yu Wang received his M.S. in Mechanical Engineering from National Taiwan University of Science and Technology in 2006. He currently works at Hon Hai Precision Industry Corporation, part of the Foxconn Technology Group. quantities of surfactant into water, Zhang et al. [7] examined the impact of surface tension on flow boiling in microchannels. Their results found no apparent reduction of wall superheat when surface tension was decreased, and eruption boiling was still observed in the $44 \mu \mathrm{m}$ diameter channel. Taking a different heating strategy, Haendler et al. [13] observed the flow boiling phenomena of methanol/water mixtures in silicon serpentine microchannels. By immersing the device into a mineral oil bath and placing it on a hot plate, phase change occurred under isothermal heating conditions. Haendler et al. [13] found no eruption meniscus for the binary system. Rather, the liquid-vapor interface extended along the microchannel, and better interface stability was observed at high superheats for methanol/water mixtures. These results suggest that the heating condition also plays a very important role in flow boiling characteristics.

The present study focused on comparing convective boiling of methanol/water mixtures in a microchannel at a low Reynolds number under different heating conditions: constant heat flux and constant wall temperature. Four different designs of the straight microchannels were used: the widths were $100 \mu \mathrm{m}$ and $150 \mu \mathrm{m}$, and artificial cavities with a diameter of $12 \mu \mathrm{m}$ were added to the bottom of the microchannels by DRIE (Deep Reactive Ion Etching). The tested mole fraction of methanol in water were 0 (pure water), 0.07, 0.3, 0.5, 0.7, 0.9, and 1 (pure methanol). The flow rate of the working fluid was set to $0.02 \mathrm{ml} / \mathrm{min}$ so that the corresponding Reynolds numbers were smaller than 12 .

\section{Experimental Setup}

This study conducted flow boiling in a microchannel with widths of $100 \mu \mathrm{m}$ and $150 \mu \mathrm{m}$. Two different types of microchannels were used: with and without cavities. For microchannels with artificial cavities, the bottom surfaces were treated to produce cavities with a depth of $30 \mu \mathrm{m}$, a radius of $12 \mu \mathrm{m}$ and a pitch of $48 \mu \mathrm{m}$. For all microchannels, the length between the centers of the two fluidic ports was fixed at $16 \mathrm{~mm}$, and the channel depth was $150 \mu \mathrm{m}$. The microchannel devices were fabricated from a $525 \mu \mathrm{m}$ thick double-sided polished silicon wafer using micromachining techniques. Initially, a $1.3 \mu \mathrm{m}$ thick layer of silicon oxide was deposited on the topside of the wafer by PECVD (Plasma Enhanced Chemical Vapor Deposition). The wafer was then turned over to perform the initial photolithography on the wafer's backside. This 8.7 $\mu \mathrm{m}$ thick photoresist (AZ P4620, Clariant) defined the fluidic ports and served as the etch mask for the first DRIE (Deep Reactive Ion Etching) step. After the completion of the first DRIE step, the remaining photoresist was removed and the wafer was flipped again for the topside processes. To open up the windows defined by the 
artificial cavities, the silicon oxide layer was patterned by the second photolithography step and etched by the first RIE (Reactive Ion Etching) step. After removing the remaining photoresist, another $8.7 \mu \mathrm{m}$ thick photoresist was spun on and patterned by the third lithography step which defined the microchannels. By exploiting the oxide layer as the etching mask, the second DRIE step etched down $30 \mu \mathrm{m}$ to produce the artificial cavities. The exposed oxide was then removed by the second RIE step, leaving the remaining photoresist as the only etch protection mask. The third DRIE step was performed to define the $150 \mu \mathrm{m}$ deep microchannels and complete the throughwafer ports. After cleaning up the photoresist and the oxide layers, the silicon wafer was anodically bonded to a Pyrex glass substrate to allow flow boiling visualization. Figure 1 shows the detailed dimensions and the SEM (Scanning Electron Microscopy) images of the microchannels after the microfabrication processes. The $20 \mu \mathrm{m}$ wide slits along the left side of the microchannel were arranged $50 \mu \mathrm{m}$ apart to gauge the length scale during the experiments.

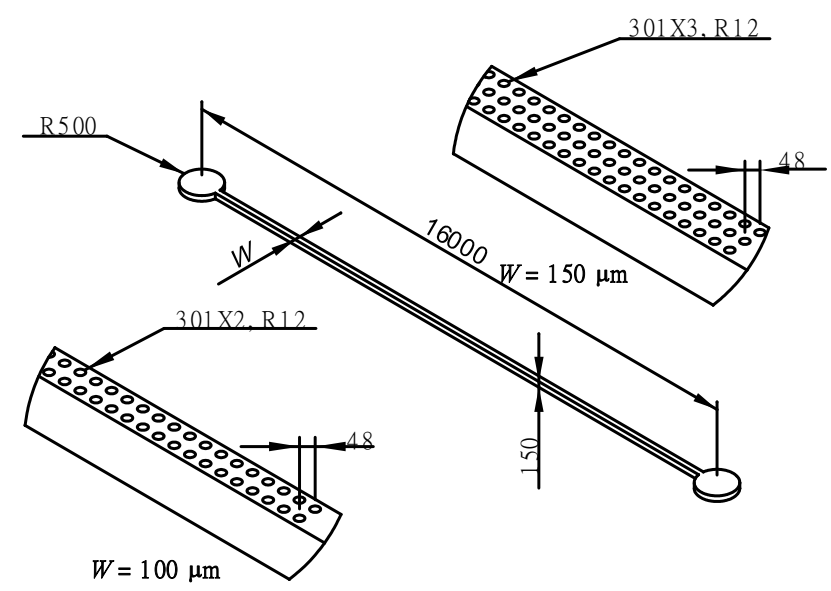

(a)
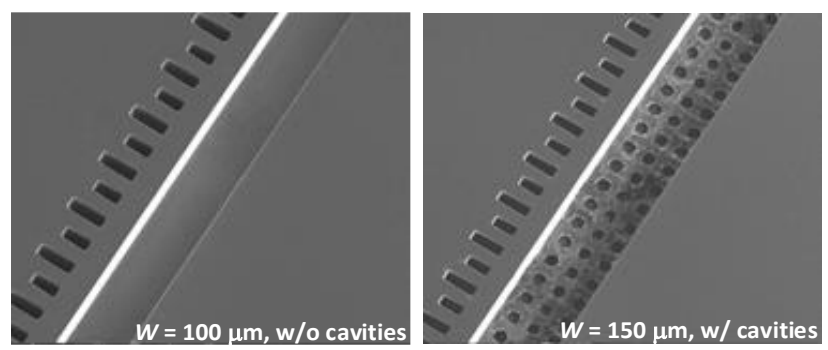

(b)

Figure 1. (a) CAD sketch with detailed dimensions and (b) SEM images of the microchannels.

Figure 2 shows the schematics of the experimental setup for different heating conditions, along with the configuration and typical readings of the temperature measurements. The apparatus was composed of the microchannel device, the heating system, the fluidic circuits and the data acquisition system. To realize isothermal microchannel wall conditions, the microchannel was immersed in a silicone oil bath on a hot plate (HP-203DN, Yeong-Shin) as shown in Fig. 2 (a). To ensure thermal uniformity, the bath was constantly stirred and its temperature was regulated by the PID (proportional-integral-derivative) controller of the hot plate. The maximal temperature deviation of the hot plate was $\pm 1^{\circ} \mathrm{C}$. However, the temperature variation of the oil bath would be much smaller than that due to its large thermal mass. A mercury-in-glass thermometer with a precision of $0.1^{\circ} \mathrm{C}$ (N60020, Amarell) was also used to monitor the bath temperature. In addition, the inlet and outlet temperatures of the working fluid were measured by T-type thermocouples.

To supply constant heat flux to the microchannel wall, a heater element made of ANSI304 stainless steel was used to hold the two electric cartridge heaters. The detailed dimensions of the heater element are provided in Fig. 2 (b). The cartridge heaters were connected to a power supply with adjustable output. As shown in Fig. 2 (c), six T-type thermocouples were embedded in the square cross-sectional upper portion of the heater element. Four of them were aligned vertically with a pitch of $12 \mathrm{~mm}$. The measurements of these thermocouples were used to determine the input heat flux $q$ " and the wall temperature $T_{\mathrm{h}}$ by the least-square fit and the Fourier Law:

$$
\begin{array}{r}
T_{\mathrm{h}}=\frac{\sum_{i=1}^{4} E_{i}^{2} \sum_{i=1}^{4} T_{i}-\sum_{i=1}^{4} E_{i} \sum_{i=1}^{4} E_{i} T_{i}}{4 \sum_{i=1}^{4} E_{i}^{2}-\left(\sum_{i=4}^{4} E_{i}\right)^{2}} \\
q^{\prime \prime}=k \frac{4 \sum_{i=1}^{4} E_{i} T_{i}-\sum_{i=1}^{4} E_{i} \sum_{i=1}^{4} T_{i}}{4 \sum_{i=1}^{4} E_{i}^{2}-\left(\sum_{i=4}^{4} E_{i}\right)^{2}}
\end{array}
$$

where $k$ is the thermal conductivity of ANSI304 stainless steel, and $E_{i}$ and $T_{i}$ are respectively the position and the temperature reading of the $i^{\text {th }}$ thermocouple. Typical temperature readings from vertically aligned thermocouples were plotted against the distance from the top surface of the heater element in Fig. 2 (d). The temperature distribution exhibited excellent linearity in the heater element among the different flow boiling regimes so that Fourier Law was valid to estimate $q$ " and $T_{\mathrm{h}}$. In addition, horizontally aligned thermocouples $\left(T_{1}, T_{5}\right.$ and $T_{6}$ ) were used to monitor the temperature uniformity along the flow direction of the microchannel. Typical temperature readings from these three thermocouples are shown in Fig. 2 (e), demonstrating a very small degree of deviation. For the binary mixtures, the wall superheat $\Delta T_{\mathrm{h}}$ was defined as the temperature difference between 
the wall and the bubble point: $\Delta T_{\mathrm{h}}=T_{\mathrm{h}}-T_{\mathrm{bp}}$. Once $q^{\prime \prime}$ and $\Delta T_{\mathrm{h}}$ were known, the heat transfer coefficient $h$ can be determined: $h=q^{\prime \prime} / \Delta T_{\mathrm{h}}$. The nearest thermocouple was 3 $\mathrm{mm}$ from the top face of the heater element with two more thermocouples arranged $4 \mathrm{~mm}$ away on each side. Measurements from these three thermocouples were monitored to examine the temperature variation of the heated surface along the flow direction of the microchannel. The temperature discrepancy on the heated surface was found to be negligible. The microchannel device and the heater element were held together by spring clamps. To reduce thermal contact resistance, thermal grease (KP92, Apus Technology) with a thermal conductivity of $10 \mathrm{~W} / \mathrm{m} \cdot{ }^{\circ} \mathrm{C}$ was applied. For both heating conditions, a syringe pump (kds210, kdScientific) was used to deliver the working fluid to the microchannel. We used methanol/water mixtures as the working fluid. The mole fractions of methanol in the water tested were 0 (pure water), 0.07, 0.3, 0.5, 0.7, 0.9, 1 (pure methanol).

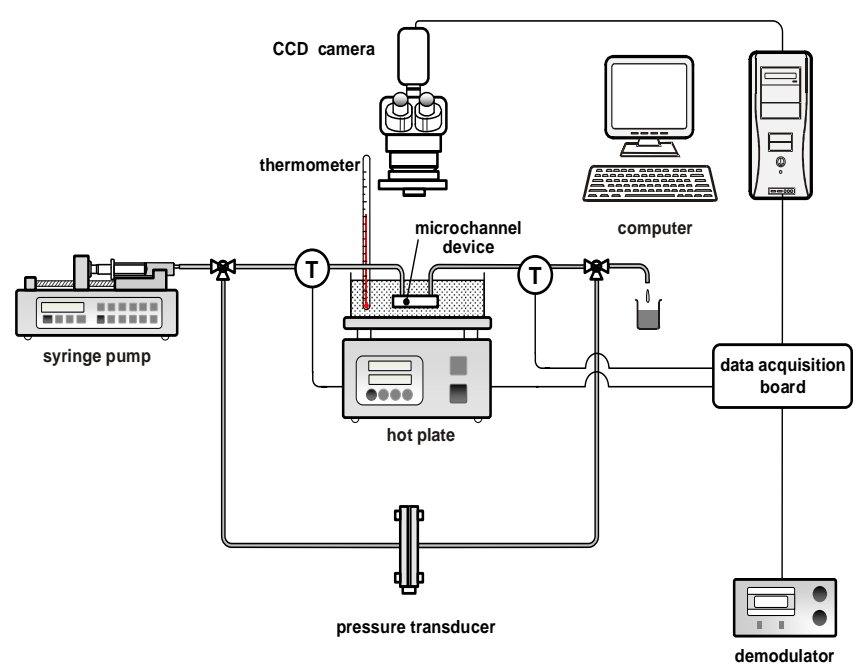

(a)

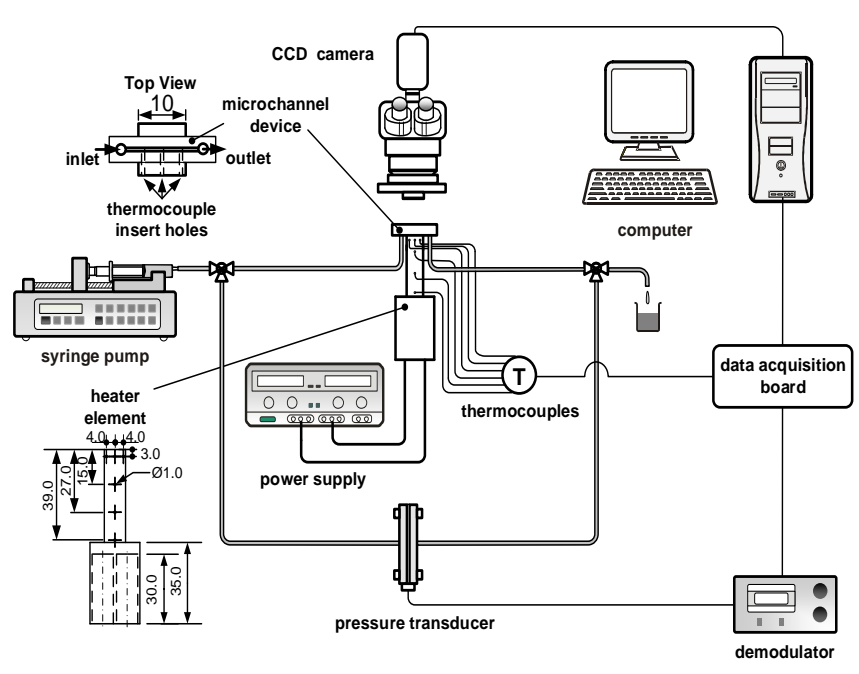

(b)

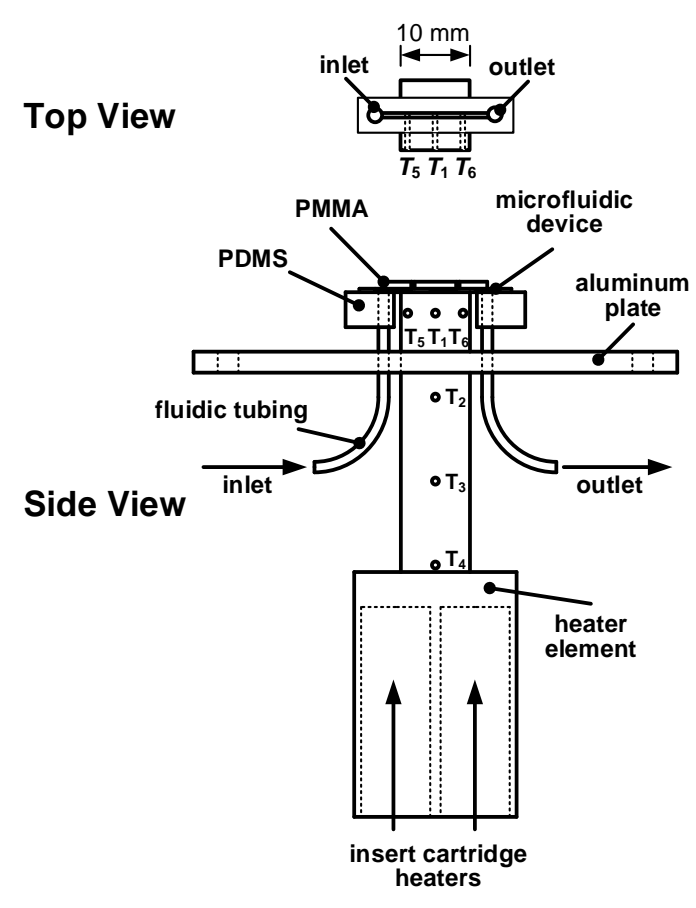

(c)

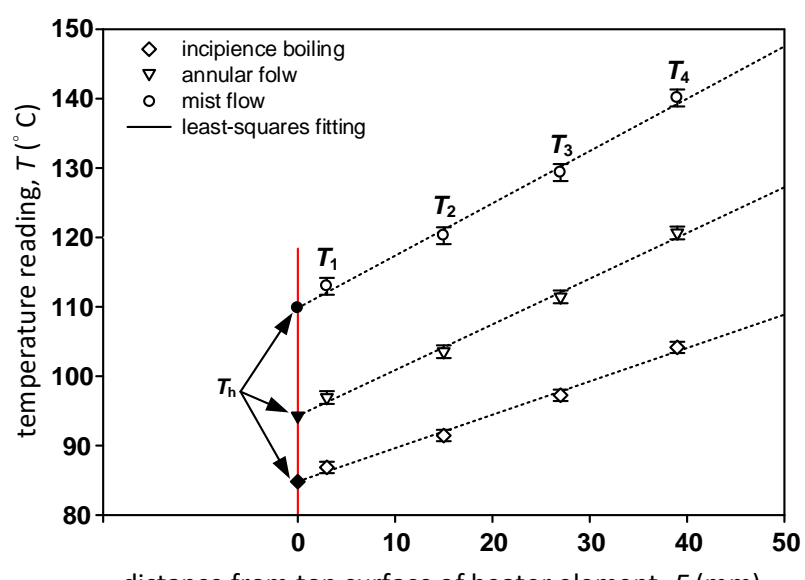

distance from top surface of heater element, $E(\mathrm{~mm})$

(d)

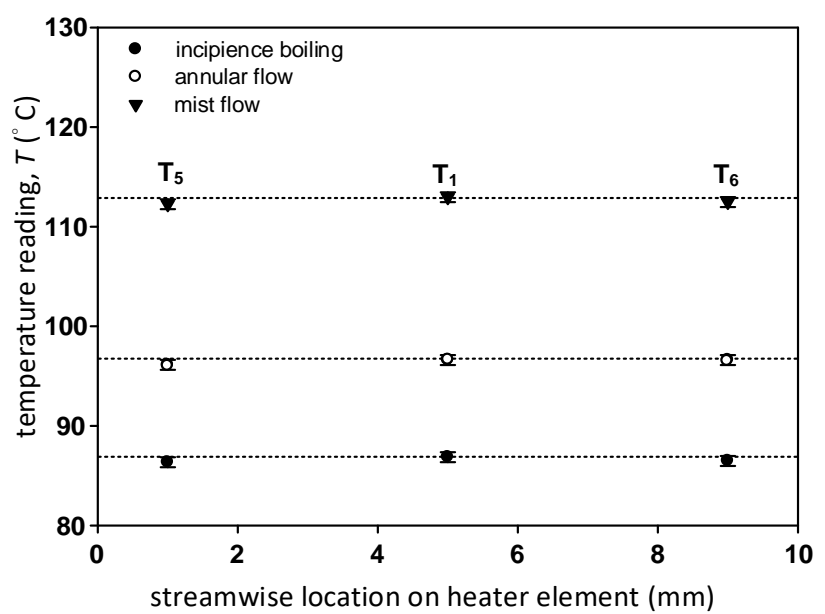

(e)

Figure 2. (a) Experimental setup for isothermal microchannel wall condition and (b) constant wall heat flux condition, unit: $\mathrm{mm}$. (c) Detailed sketch of the heater element. (d) Typical temperature readings of thermocouples aligned vertically and (e) horizontally. 
Prior to the experiments, the working fluid was preboiled for several minutes to eliminate dissolved gas. The flow rate was set to $0.02 \mathrm{ml} / \mathrm{min}$. Depending on the mixture content, the corresponding Reynolds number varied between 5.3 and 11.5 for the $100 \mu \mathrm{m}$ wide microchannel, and between 4.4 and 9.6 for the $150 \mu \mathrm{m}$ wide microchannel. The pressure difference between the inlet and outlet of the microchannel was measured by a differential pressure transducer (DP103, Validyne) connected to a demodulator (CD23, Validyne). The raw measurements of temperature and pressure were taken and recorded by a PC-based data acquisition system with LabVIEW (National Instruments). During the experiments, the flow boiling process in the microchannel was recorded by a $30 \mathrm{fps}$ CCD camera (CV-S3300, jai).

Table 1. Overall uncertainties.

\begin{tabular}{ll}
\hline Quantity & Overall uncertainty \\
\hline Wall Superheat & $\pm 1.5^{\circ} \mathrm{C}$ \\
Input Heat Flux & $\pm 7 \%$ \\
Pressure Difference & $\pm 7.4 \mathrm{~Pa}$ \\
Volumetric Flow Rate & $\pm 2 \%$ \\
Mole Fraction & $\pm 0.0008 \%$ \\
Heat Transfer Coefficient & $\pm 7.1 \%$ \\
\hline
\end{tabular}

Table 1 lists the overall uncertainties of the measurements and calculated quantities in this study. Considering the error propagation [14], the relative uncertainty of heat transfer coefficient $U_{h} / h$ was determined by

$$
\frac{U_{h}}{h}=\left[\left(\frac{U_{q^{\prime \prime}}}{q^{\prime \prime}}\right)^{2}+\left(\frac{U_{\Delta T_{h}}}{\Delta T_{\mathrm{h}}}\right)^{2}\right]^{1 / 2}
$$

where the relative uncertainty of superheat $U_{\Delta T_{h}} / \Delta T_{h}$ was given by

$$
\frac{U_{\Delta T_{\mathrm{h}}}}{\Delta T_{\mathrm{h}}}=\left[\left(\frac{U_{T_{\mathrm{h}}}}{\Delta T_{\mathrm{h}}}\right)^{2}+\left(\frac{U_{T_{\mathrm{bP}}}}{\Delta T_{\mathrm{h}}}\right)^{2}\right]^{1 / 2}
$$

The uncertainty of the bubble point $U_{T_{\mathrm{bp}}}$ was about $\pm 1 \%$. As seen in Fig. 2(d), the uncertainties of the wall superheat $U_{T_{h}}$ and heat flux $U_{q^{\prime \prime}}$ depend on the linear regression of the temperature readings. Therefore, $U_{T_{h}}$ could be expressed as

$$
\begin{aligned}
U_{T_{\mathrm{h}}} & =\left\{\sum_{i=1}^{4}\left[\frac{\sum_{k=1}^{4} E_{k}^{2}-\sum_{k=1}^{4} E_{k}}{4 \sum_{k=1}^{4} E_{k}^{2}-\left(\sum_{k=1}^{4} E_{k}\right)^{2}}\right]_{T}^{2}+\right. \\
& +\sum_{i=1}^{4}\left[\frac{2 E_{i} \sum_{k=1}^{4} T_{k}-\left(\sum_{k=1}^{4} E_{k} T_{k}+T_{i} \sum_{k=1}^{4} E_{k}\right)}{\left[4 \sum_{k=1}^{4} E_{k}^{2}-\left(\sum_{k=1}^{4} E_{k}\right)^{2}\right]^{2}}-\right. \\
& \left.\left.\frac{\left(\sum_{k=1}^{4} E_{k}^{2} \sum_{k=1}^{4} T_{k}-\sum_{k=1}^{4} E_{k} \sum_{k=1}^{4} E_{k} T_{k}\right)\left(8 E_{i}-2 \sum_{k=1}^{4} E_{k}\right)}{\left[4 \sum_{k=1}^{4} E_{k}^{2}-\left(\sum_{k=1}^{4} E_{k}\right)^{2}\right]^{2}}\right]_{E}^{2}\right\}^{1 / 2}
\end{aligned}
$$

And $U_{q "}$ was the product of the thermal conductivity $k$ and the uncertainty on the slope of the fitted line:

$$
\begin{aligned}
U_{q^{\prime \prime}} & =k\left\{\sum_{i=1}^{4}\left[\frac{4 E_{i}-\sum_{k=1}^{4} E_{k}}{4 \sum_{k=1}^{4} E_{k}^{2}-\left(\sum_{k=1}^{4} E_{k}\right)^{2}}\right]_{T}^{2}\right. \\
& +\sum_{i=1}^{4}\left[\frac{\left(4 T_{i}-\sum_{k=1}^{4} T_{k}\right)\left[4 \sum_{k=1}^{4} E_{k}-\left(\sum_{k=1}^{4} E_{k}\right)^{2}\right]}{\left[4 \sum_{k=1}^{4} E_{k}^{2}-\left(\sum_{k=1}^{4} E_{k}\right)^{2}\right]^{2}}-\right. \\
& \left.\frac{\left(4 \sum_{k=1}^{4} E_{k} T_{k}-\sum_{k=1}^{4} E_{k} \sum_{k=1}^{4} T_{k}\right)\left(8 E_{i}-2 \sum_{k=1}^{4} E_{k}\right)}{\left[4 \sum_{k=1}^{4} E_{k}^{2}-\left(\sum_{k=1}^{4} E_{k}\right)^{2}\right]^{2}} U_{E}^{2}\right]^{1 / 2}
\end{aligned}
$$

In Eqs. (4) and (5), $U_{T}$ and $U_{E}$ were respectively the overall uncertainties of the temperature measurement and the location of the thermocouple. Since the input heat flux was determined by the least-squares regression of temperature readings, uncertainties regarding the thermocouple locations, i.e., machining precision, were propagated through calculation. As a result, the uncertainty of the input heat flux was relatively high.

\section{Methanol/Water Mixtures}

The working fluids in the present study were methanol/water mixtures. These particular fluid mixtures were chosen because of their high dependency of surface tension on concentration. Methanol/water mixtures were categorized as positive mixtures, where the more volatile liquid had a lower surface tension. For a given mole fraction, the bubble-point and the dew-point temperatures of the mixtures could be estimated from the 
liquid-vapor phase equilibria [15]. According to Raoult's law, the saturation pressure of the mixture $P$ is given by

$$
P=x \gamma_{1} P_{1, \text { sat }}+(1-x) Y_{2} P_{2, \text { sat }}
$$

where $x$ is the mole fraction, and $P_{1, \text { sat }}$ and $P_{2, \text { sat }}$ are respectively the saturation pressures for pure methanol and water. $P_{1, \text { sat }}$ and $P_{2, \text { sat }}$ are temperature dependent. Herein, $\gamma_{1}$ and $\gamma_{2}$ are the activity coefficients of the binary mixture which could be calculated from Wilson's equation:

$$
\begin{aligned}
& \ln \gamma_{1}=-\ln \left[x+\mathrm{A}_{12}(1-x)\right]+(1-x) . \\
& {\left[\frac{\mathrm{A}_{12}}{x+\mathrm{A}_{12}(1-x)}-\frac{\mathrm{A}_{21}}{\mathrm{~A}_{21} x+(1-x)}\right] } \\
& \ln \gamma_{2}=-\ln \left[(1-x)+\mathrm{A}_{21} x\right]-x . \\
& {\left[\frac{\mathrm{A}_{12}}{x+\mathrm{A}_{12}(1-x)}-\frac{\mathrm{A}_{21}}{\mathrm{~A}_{21} x+(1-x)}\right] }
\end{aligned}
$$

The constants $A_{12}$ and $A_{21}$ are taken from the literature [16]. Given the condition that the saturation pressure at the bubble point should equal to the system pressure, the bubble-point temperature could be determined iteratively from Raoult's law. Similarly, the dew-point temperature could be estimated by replacing $x$ in Eqs. (6), (7a), and (7b) with the vapor mole fraction $y$, which was given by

$$
y=\frac{x Y_{1} P_{1, \text { sat }}}{P}
$$

Under a pressure of $1 \mathrm{~atm}$, Fig. 3 illustrates the phase equilibrium diagram and the variation of the equilibrium contact angle on a clean silicon wafer with the mole fraction. The equilibrium contact angle was measured using an image of a sessile drop of methanol/water mixtures at the point of intersection between the drop contour and the projection of the surface of a new silicon wafer without cleaning. Conventionally, $y$ and $x$ are respectively referred to as the vapor and liquid mole fraction of the more volatile component (methanol). For methanol/water mixtures, the dew-point temperatures $T_{\mathrm{d}}$ are always higher than the bubble-point temperatures $T_{\mathrm{bp}}$, and both of these temperatures are strongly concentration-dependent. As shown in Fig. 3 (a), the maximal temperature difference between the bubble point and dew point is approximately $15^{\circ} \mathrm{C}$ at $x=0.3$. On the other hand, Fig. 3 (b) shows that the static contact angle decreased from $52.4^{\circ}$ at $x=0$ to $5.6^{\circ}$ at $x=0.9$. For pure methanol, the contact angle was too small to be measured. For experiments, the chosen mole fractions of methanol in water were 0 (pure water),
$0.07,0.3,0.5,0.7,0.9$, and 1 (pure methanol). The physical properties of the methanol/water mixtures were evaluated based on the methods and information provided by Ohe [16], Poling, et al. [15], and Yaws [17].

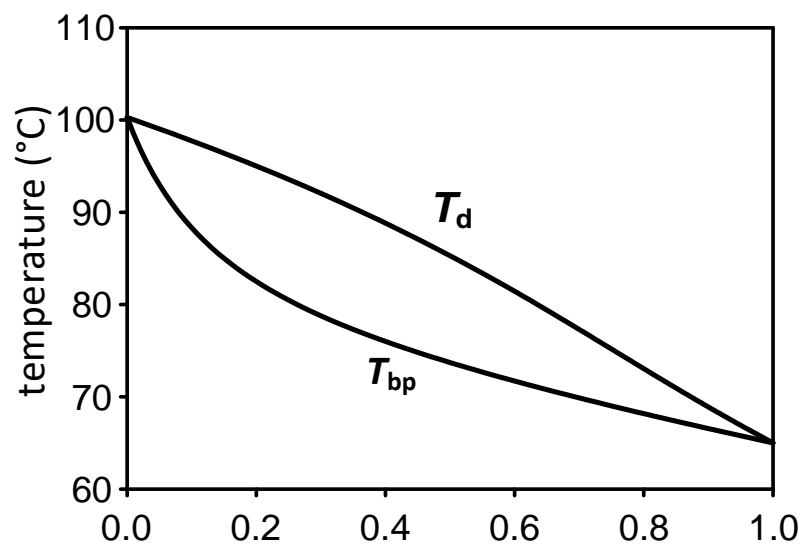

liquid mole fraction of methanol in water $x$

(a)

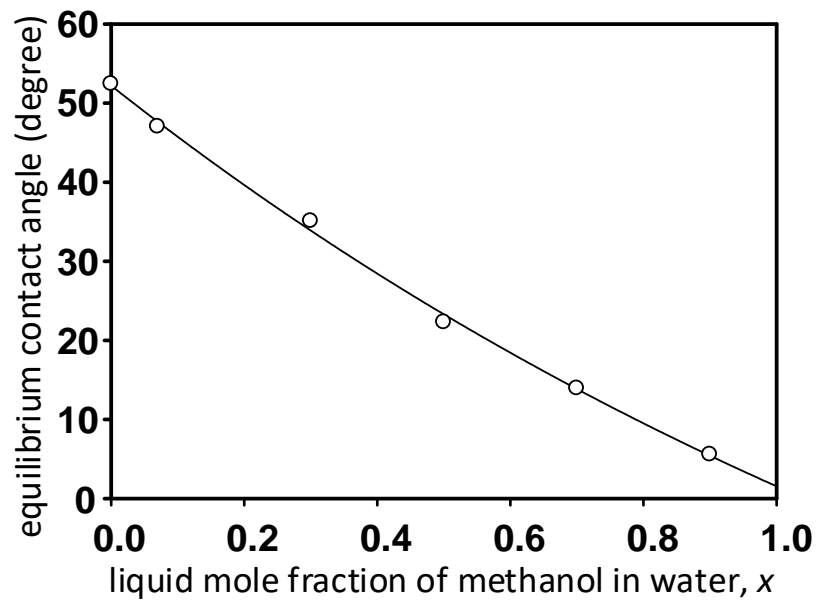

(b)

Figure 3. (a) Phase equilibrium diagram at $1 \mathrm{~atm}$, and (b) the variation of equilibrium contact angle with mole fraction for methanol/water mixtures on a silicon wafer. The solid curve was a best fit to the data.

According to the Hsu model of onset of boiling, whether the cavity was active depended on the wall superheat $\Delta T_{\mathrm{h}}$ and the thickness of the thermal boundary layer $\delta_{\mathrm{t}}$ [18]. If the bulk liquid reached its saturation temperature $T_{\text {sat }}$ at a given liquid pressure $P_{1}$, the size range of active sites could be predicted by

$$
\left\{\begin{array}{l}
r_{\mathrm{c}, \max } \\
r_{\mathrm{c}, \text { min }}
\end{array}\right\}=\frac{\delta_{\mathrm{t}}}{4}\left\{1 \pm\left[1-\frac{12.8 \sigma T_{\mathrm{sat}}\left(P_{)}\right)}{\rho_{\mathrm{v}} h_{\mathrm{v}} \delta_{\mathrm{t}} \Delta T_{\mathrm{h}}}\right]^{1 / 2}\right\}
$$

where $r_{c, \text { max }}$ and $r_{c, \min }$ were respectively the upper and lower bounds of the radius of the active cavities, while $\rho_{\mathrm{v}}$ and $h_{\mathrm{l}}$ were respectively the vapor density and the latent heat of vaporization of the working fluid. Near the wall, the thermal layer thickness could be approximated as $k_{1} / h$, where $k ı$ and $h$ are respectively the thermal conductivity 
of liquid and the heat transfer coefficient. According to Peng et al. [12], the heat transfer coefficient is about 4000 $\mathrm{W} / \mathrm{m}^{2} \cdot{ }^{\circ} \mathrm{C}$ for flow boiling in microchannels. If we assumed a wall superheat of $3^{\circ} \mathrm{C}$ was needed to initiate and sustain nucleate boiling, the ranges of active sites are 9.8-75 $\mu \mathrm{m}$ for water and 2.9-21 $\mu \mathrm{m}$ for methanol at $1 \mathrm{~atm}$. This study uses a cavity radius of $12 \mu \mathrm{m}$ in the microchannel design.

\section{Results and Discussions}

For convective boiling in microchannels at low Reynolds numbers, the typical sequence of flow regimes was observed and depicted in Fig. 4. Slug flow manifested near the incipience of boiling. In the slug flow regime, bubbles appear from the edge of the microchannel or the artificial cavities. As bubbles grow, they quickly coalesce into vapor slugs that are carried away by the flow. With the increase of quality, the vapor slug grew in length and the length of the liquid section between adjacent vapor slugs decreased. As a result, vapor slugs emerged at a higher frequency. Eventually, a continuous vapor core was observed and the flow pattern transformed into the annular flow regime. In the annular flow regime, the vapor core was surrounded by a thin liquid film wetting the circumference of the microchannel. The vapor-liquid interface fluctuated frequently in the transverse direction, exhibiting transient characteristics. Entrainment of fine droplets in the vapor core was also observed. A further increase of the quality resulted in the thinning of the liquid film. Ultimately, the surface tension was unable to maintain the vapor-liquid interface, and the liquid film ruptured into several small patches on the wall. The small liquid blobs quickly evaporated and disappeared, but the vapor flow would introduce more liquid chunks. This phenomenon is referred to as the sheet breakup regime. Once liquid patches were dried out, the microchannel was completely occupied by mist and the mist flow regime was achieved. Figures 5 and 6 respectively illustrate the influences of the mole fraction on the flow boiling regime under the isothermal microchannel and constant heat flux conditions. The wall superheat was defined as the temperature difference between the heated surface/oil both and the bubble point. Each data point indicates the superheat associated with the transition of two regimes for a given mole fraction. The solid symbols label the cases of the plain microchannels while the open symbols mark the cases of the microchannels with artificial cavities. Comparing Figs. 5 and 6 , we find that the heating condition had a profound effect on the regime map of convective boiling in the microchannel. Under isothermal conditions, the configuration of the microchannel had little impact on the regime map of flow boiling as depicted in Fig. 5. In addition, boiling only initiated when the wall temperature slightly exceeded the bubble-point temperature, and the wall superheat associated with the onset of heterogeneous nucleation was not influenced by the mixture composition. Similar to the phenomena found under the constant heat flux condition [18], the bubble stopped or even reversed its movement direction due to the large evaporating momentum force under the isothermal wall condition (See videos S1 and S2). In contrast, Fig. 6 demonstrates that the bubble could possibly emerge when the wall was still subcooled under the constant heat flux condition, especially for pure water $(x=0)$ and methanol/water mixtures of $x=0.5$ and 0.7 in the $100 \mu \mathrm{m}$ wide microchannel. For $W=150 \mu \mathrm{m}$, there was no slug flow regime and the annular flow regime immediately emerged once boiling commenced. As a result, incipience of boiling always occurred when the wall temperature was above the bubble point for $W=150 \mu \mathrm{m}$. The only exception was water. Due to its large surface tension, gas could be easily trapped in some of the cavities on the surface or corners of the microchannel during the filling process. Therefore, the appearance of growing bubbles under subcooled conditions was inevitable for pure water. In the $150 \mu \mathrm{m}$ wide microchannel, placing artificial cavities on the bottom surface also helped to reduce the superheat associated with the onset of boiling for $x=0.5$ and 0.7 .

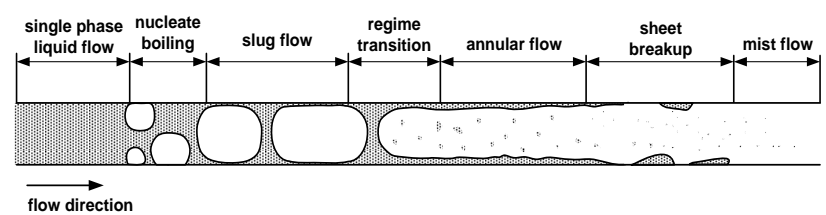

Figure 4. Flow boiling regimes in the microchannel.

Due to the limited space in the microchannel, slug flow only extended up a few degrees of superheat, and annular flow was quickly formed as the slug bubble expanded. Under the isothermal condition, annular flow regime was presented in a wide range of wall superheat for all mole fractions. We found that the superheat span associated with the annular flow regime shrank as the mole fraction increased. However, annular flow barely existed for mixtures with high contents of water or methanol ( $x=0,0.1,0.9 \& 1)$ when the microchannel was heated under the constant heat flux condition. Rather, as the elongated bubble moved downstream, evaporation of the liquid film directly resulted in locally intermittent or sustained dryout of the wall, followed by sheet breakup or mist flow.

Sheet breakup was found to be unique to the constant heat flux condition (See Video S3). Because sharp edges might pinch the liquid-vapor interface and crevices help to retain liquid patches, the sheet breakup regime could survive at much higher wall superheats in 
microchannels with artificial cavities for mixtures with higher water content $(x=0.07 \& 0.3)$. At $x=0.07$, adding the artificial cavities extended the upper bound of the superheat associated with the sheet breakup regime from $16^{\circ} \mathrm{C}$ to $43.7^{\circ} \mathrm{C}$ in the $100 \mu \mathrm{m}$ wide microchannel. Nevertheless, this effect diminished and the opposite was found for $x \geq 0.5$. We speculate that the features on the dimpled surface could be regarded as fins such that the extended surface helped to enhance heat transfer and decrease the upper bound of superheat for sheet breakup by approximately $10^{\circ} \mathrm{C}$. For methanol/water mixtures, both the surface tension and the latent heat of vaporization decreased as mole fraction increased. Therefore, sheet breakup at high superheat was controlled by interfacial forces for mixtures with low mole fractions while heat transfer dominated for mixtures with high mole fractions. The leverage between these two mechanisms resulted in a prominent sheet breakup regime for $x=0.3$, as seen in Fig. 6 . Another factor that might contribute to the expansive sheet breakup regime was the substantial difference in bubble-point and dewpoint temperatures for $x=0.3$. The separation of the bubble point and dew point allows vapor and liquid to coexist over a wide range of temperatures, and dramatically altered the boiling characteristics of binary mixtures in microchannels. For the methanol/water mixtures, the value of $\left|T_{d}-T_{b p}\right|$ attained a maximum at a liquid composition of $x=0.3$ for which the sheet breakup regime persisted up to $69.3^{\circ} \mathrm{C}$ of superheat in the $100 \mu \mathrm{m}$ wide microchannel with cavities. As mole fraction increased to 0.9 , the deviation of the bubble point and dew point was below $2^{\circ} \mathrm{C}$. Rapid evaporation occurred at $29.4^{\circ} \mathrm{C}$ of superheat and mist flow was immediately established.

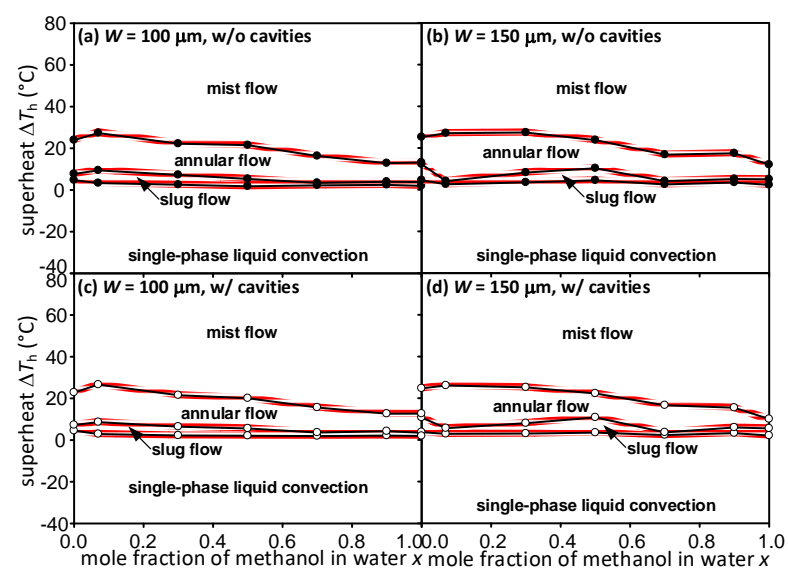

Figure 5. Influence of mole fraction on flow boiling regimes under the isothermal microchannel wall condition: (a) $W=100 \mu \mathrm{m}$ without artificial cavity, (b) $W=150 \mu \mathrm{m}$, without artificial cavity, (c) $W=100 \mu \mathrm{m}$ with artificial cavities, and (d) $W=150 \mu \mathrm{m}$, with artificial cavities.

Although the upper bounds of the annular flow were comparable under both heating conditions, no sheet breakup was observed when the microchannel was heated under the isothermal condition. As the temperature of the oil bath increased, the liquid flow became unstable and oscillatory. While vapor flowed continuously forward in the core, the surrounding liquid was sometimes trapped by the corners of the microchannel, resulting in high shear and a distorted liquid-vapor interface (See Video S4). However, the liquid film continued to blanket the microchannel wall and no liquid patch was observed. For $x=0.3$, complete dryout of the microchannel wall was found at a superheat as low as $21.5^{\circ} \mathrm{C}$ in the $100 \mu \mathrm{m}$ wide microchannel with cavities, much lower than that $\left(\Delta T_{\mathrm{h}}=69.3^{\circ} \mathrm{C}\right)$ under the constant heat flux condition.

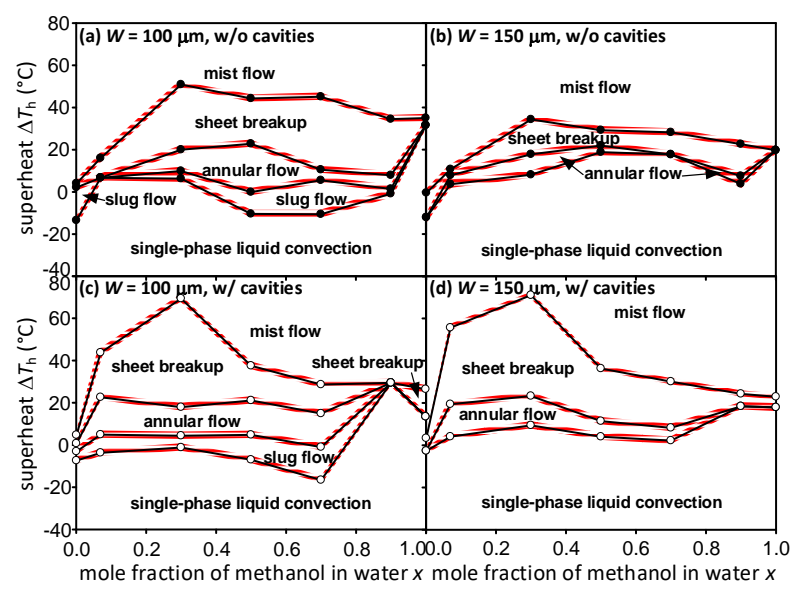

Figure 6. Influence of mole fraction on flow boiling regimes under the constant microchannel heat flux condition: (a) $W=100 \mu \mathrm{m}$ without artificial cavity, (b) $W=150 \mu \mathrm{m}$, without artificial cavity, (c) $W=100 \mu \mathrm{m}$ with artificial cavities, and (d) $W=150 \mu \mathrm{m}$, with artificial cavities.

Depending on the heating condition, the influence of the composition on characteristics of convective boiling in a microchannel could be very different. Under the isothermal condition, the increase of the mole fraction of methanol in water decreased the superheat associated with regime transitions, but had little impact on the onset of nucleation. In contrast, the composition played a prominent role in the regime map of flow boiling when the microchannel was heated under the constant heat flux condition. For $x=0$ (pure water) and 1 (pure methanol), each regime was maintained only over a small range of superheat, and nucleation quickly turned into mist flow. On the other hand, different boiling regimes extended over wide spans of superheats when methanol was blended with water. With the addition of even a small amount of methanol ( $x=0.07$ and 0.3 ), the mist flow did not emerge until the superheat was very high. This was particularly evident when flow boiling took place in the microchannel with cavities. A high methanol content $(x=$ 0.9 ) made it difficult to sustain slug flow or annular flow in a microchannel with cavities. Instead, nucleation led directly to mist flow or sheet breakup regime. This was 
ascribed to the reduction of the contact angle and surface tension at high mole fractions. To make the artificial cavities effective, air or vapor had to be trapped in the crevices. The idealized vapor trapping process is illustrated in Fig. 7 [19], from which the condition for vapor entrapment in the cavity could be stated as

$$
\theta_{\mathrm{adv}} \geq \tan ^{-1}\left(2 \mathrm{r}_{\mathrm{c}} / \mathrm{D}_{\mathrm{c}}\right)
$$

where $\vartheta_{\text {adv }}$ is the contact angle of the advancing liquid front, and $r_{c}$ and $D_{c}$ are respectively the radius and depth of the artificial cavity. In our microchannel design, $r_{c}=12$ $\mu \mathrm{m}$ and $D_{c}=30 \mu \mathrm{m}$. Therefore, $\vartheta_{\text {adv }}$ had to be larger than $38.7^{\circ}$ to successfully trap vapor in the cavity. As shown in Fig. 3 (b), the contact angle decreased as mole fraction increased, and so did the surface tension. Hence, it is difficult to have active nucleation sites for mixtures with large mole fractions. From Fig. 3 (b), the static contact angles were smaller than $15^{\circ}$ for both $x=0.9$ and 1 on the silicon surface. Even though the advancing contact angle was usually larger than the equilibrium contact angle due to contact angle hysteresis, neither slug flow nor annular flow regimes were observed for $x>0.7$. Instead, the weak surface tension resulted in a burst of mist flow or sheet breakup once boiling was initiated.

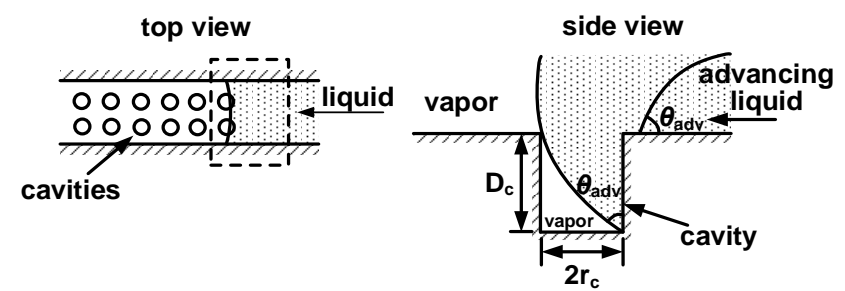

Figure 7. Idealized model of vapor trapping process in artificial cavity.

Figure 8 shows the boiling curves for flow boiling of methanol/water mixtures with various mole fractions in different microchannels under the constant heat flux condition. Unlike the results of Liu and Garimella conducted at much higher mass fluxes [20], the boiling curves only experienced a small jump when nucleation occurred, i.e., a moderate change in slope was observed at boiling incipience. Although heat flux continued to increase with the superheat, the slopes remained nearly consistent throughout the entire flow boiling process. Compared to the channel width, the presence of artificial cavities played a more important role in flow boiling heat transfer in the microchannel. Because the surface area is augmented by adding artificial cavities to the bottom of the microchannel, heat transfer was actually improved.

This was particularly evident for $W=100 \mu \mathrm{m}$. On the other hand, increased microchannel width only resulted in a higher heat flux under single-phase liquid convection. Once boiling occurred, nucleation dominated and the boiling curves showed no distinction. For microchannels with artificial cavities, flow boiling in the narrower microchannel resulted in a slight enhancement in flow boiling heat transfer for $x=0,0.3$, and 1 . It appears that flow boiling in a narrower microchannel with artificial cavities helps to accentuate the influence of the composition. To further discuss this effect, we calculated the heat transfer coefficients $h$ from the boiling curves:

$$
h=q^{\prime \prime} /\left(T_{\mathrm{h}}-T_{\mathrm{bp}}\right)=q^{\prime \prime} / \Delta T_{\mathrm{h}}
$$

where $T_{\mathrm{h}}$ and $T_{\mathrm{bp}}$ were respectively the wall temperature and the bubble-point temperature. The variations of the heat transfer coefficient with the wall superheat are shown in Fig. 9 for flow boiling in different microchannels. We found that the heat transfer coefficient decreased as the superheat increased. The mass fluxes used in the current study were in the range of $14.8-22 \mathrm{~kg} / \mathrm{m}^{2} \cdot \mathrm{s}$, much lower than those used in previous studies [20-22]. Indeed, Kew and Cornwell [21] found that the heat transfer coefficient actually showed different trends for high and low mass fluxes. At low mass fluxes, the contribution of the nucleate boiling effect was relatively weak compared to the transport in flow boiling in a microchannel. As seen in Fig. 6, the most common regime above the bubblepoint temperature was annular flow or sheet breakup. Both regimes produced partial dryout on the microchannel wall, which resulted in a decrease in heat transfer with the increase of quality [22]. In Fig. 9 (d), the jumps are clear indications of the onset of boiling, which is usually accompanied by enormous rises in pressure.

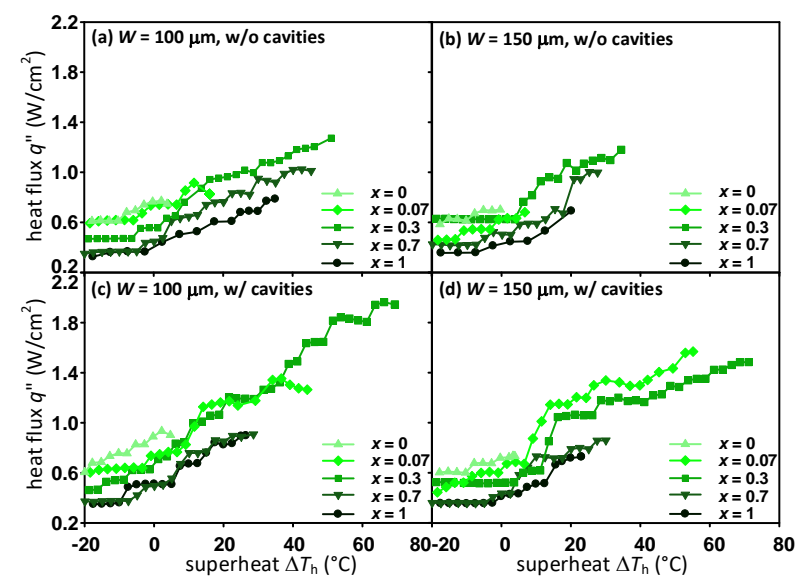

Figure 8. Boiling curves for methanol/water mixtures in a microchannel heated under the constant heat flux condition: (a) $W=100 \mu \mathrm{m}$ without artificial cavity, (b) $W=150 \mu \mathrm{m}$, without artificial cavity, (c) $W=100 \mu \mathrm{m}$ with artificial cavities, and (d) $W=150 \mu \mathrm{m}$, with artificial cavities.

Although the heat transfer coefficients for $x=0.07$ and 0.3 nearly coincided to each other, it is clear that the heat transfer coefficient decreases with the mole fraction. A significant increment in heat transfer coefficients was found for $x=0.07$ compared to that for $x=1$. Due to

ausMT Vol. 6 No. 2 (2016) 
additional methanol evaporation as the working fluid flowed through the microchannel, the liquid mole fraction deceased and the local bubble point increased in the downstream direction. Therefore, part of the heat transferred to the liquid was used to retain the fluid at saturation conditions and evaporation was concealed. As the quality increased, the vapor core was accelerated such that the forced convective effect became more important and the suppression of nucleation led to a decrease in the heat transfer coefficient.

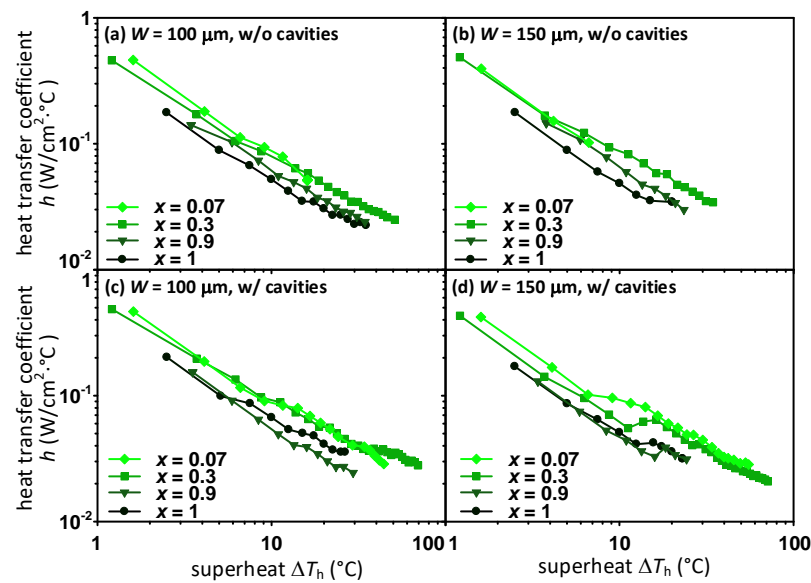

Figure 9. Heat transfer coefficient vs. wall superheat for methanol/water mixtures in a microchannel heated under the constant heat flux condition: (a) $W=100 \mu \mathrm{m}$ without artificial cavity, (b) $W=150 \mu \mathrm{m}$, without artificial cavity, (c) $W=100 \mu \mathrm{m}$ with artificial cavities, and (d) $W$ $=150 \mu \mathrm{m}$, with artificial cavities.

In this study, the CHF (Critical Heat Flux) conditions were identified as the transition corresponding to complete dryout of the liquid film on the microchannel wall. The variations of $\mathrm{CHF}$ with mole fraction are shown in Fig. 10. CHF was found to be strongly influenced by the composition of the mixtures under the constant heat flux condition. Adding methanol in water clearly heightened the $\mathrm{CHF}$, and maxima in the $\mathrm{CHF}$ values were found at or near the location where $|y-x|$ reached a maximum, as was the case in macroscopic flow boiling [18]. For methanol/water mixtures, the mole fraction corresponding to a maximum value of $|y-x|$ and $\mid T_{d}-$ $T_{\text {bp }} \mid$ was $x=0.23$ and 0.3 , respectively. $A$ rapid improvement of CHF was observed for $x=0.07$ and 0.3. At $x=0.3$, the span of the superheat corresponding to the sheet break regime was so wide that mist flow was always reached at the highest superheats among all tested mole fractions. This helped to elevate the allowable input heat flux without burnout, and higher CHF was attained. Consequently, maximal CHF was obtained at $x=0.3$ except the $150 \mu \mathrm{m}$ wide microchannel with cavities.

Moreover, adding artificial cavities to the bottom wall of the microchannels helped to augment the CHF condition for mixtures of $x=0.07$ and 0.3. Since artificial cavities tended to trap liquid, sheet breakup regime was retained at high superheats without complete dryout. For $x=0.07$ and 0.3 , CHF was increased by $51.7 \%$ and $74.7 \%$ respectively for microchannels with artificial cavities. For $x \leq 0.3$, increasing the microchannel width from $100 \mu \mathrm{m}$ to $150 \mu \mathrm{m}$ led to a reduction in the CHF value. This was because the Reynolds numbers or mass flux in the wider microchannel were slightly smaller than those in the narrower ones for a given flow rate. Near the CHF condition, heat transfer was dominated by forced convection. Hence, the decrease in mass flux reduced the flow boiling heat transfer. An average decrease of $\mathrm{CHF}$ was $10 \%$ as the microchannel was widened from $100 \mu \mathrm{m}$ to $150 \mu \mathrm{m}$.

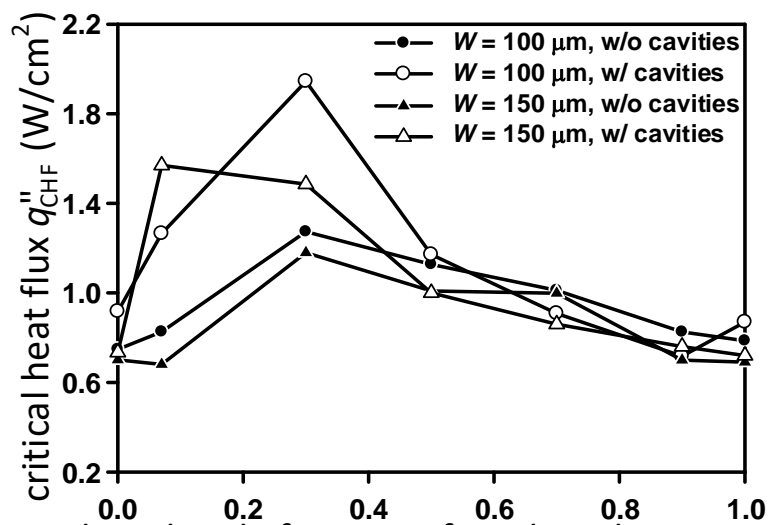

liquid mole fraction of methanol in water $x$

Figure 10. Comparison of the variations of $\mathrm{CHF}$ with mole fraction for flow boiling of methanol/water mixtures in a microchannel heated under the constant heat flux condition.

\section{Conclusion}

The effect of heating conditions on the convective boiling of methanol/water mixtures in a microchannel is explored and the role composition plays in the flow boiling heat transfer characteristics is discussed. Key findings are summarized as follows:

1. For flow boiling of methanol/water mixtures in microchannels, the heating condition played a significant role in the regime map. Under the isothermal condition, heterogeneous nucleation only occurred at superheated conditions. In contrast, bubbles could emerge at subcooled condition under constant heat flux conditions.

2. Mixture content strongly affected the regime map under constant heat flux conditions, but had little impact under isothermal conditions. Sheet breakup, which occurred when the liquid film of the annular flow ruptured, was uniquely observed under constant heat flux conditions.

3. For $x=0.07$ and 0.3 , the extension of the sheet breakup regime over a wider range of wall superheat resulted in much higher $\mathrm{CHF}$ values.

4. Due to weak surface tensions, slug flow and annular flow regimes rarely existed for $x>0.7$. Incipience of ausMT Vol. 6 No. 2 (2016) 
boiling directly burst into sheet breakup or mist flow regime.

5. Under constant heat flux conditions, no slug flow was observed in the $150 \mu \mathrm{m}$ wide microchannels.

6. In general, the heat transfer coefficient decreased with increasing mole fraction. A slight increase of heat transfer coefficients was occasionally observed due to the onset of boiling. However, this augmentation quickly diminished at higher superheats.

7. The CHF condition was elevated by having artificial cavities in the microchannel and by decreasing the microchannel width.

\section{Acknowledgments}

This work was supported by the National Science Council of Taiwan under grant numbers NSC94-2212-E011-039 and NSC95-2221-E-011-160.

\section{References}

[1] Y. Hong, N. Ashgriz, and J. Andrews, "Experimental Study of Bubble Dynamics on a Micro Heater Induced by Pulse Heating," Journal of Heat Transfer, vol. 126, no. 2, pp. 259-271, 2004.

doi: $10.1115 / 1.1650388$

[2] J.-H. Tsai and L. Lin, "A thermal-bubble-actuated micronozzle-diffuser pump," IEEE Journal of Microelectromechanical Systems, vol. 11, no. 6, pp. 665-671, 2002.

doi: 10.1109/JMEMS.2002.802909

[3] Yoshida, S. Tanaka, H. Hiraki, and M. Esashi, "A micro fuel reformer integrated with a combustor and a microchannel evaporator," Journal of Micromechnics and Microengineering, vol. 16, no. 9, pp. S191-S197, 2006.

doi: $10.1088 / 0960-1317 / 16 / 9 /$ S04

[4] W. Qu and I. Mudawar, "Flow boiling heat transfer in two-phase micro-channel heat sinks. I. Experimental investigation and assessment of correlation methods," International Journal of Heat and Mass Transfer, vol. 46, no. 15, pp. 2755-2771, 2003. doi: 10.1016/S0017-9310(03)00041-3

[5] J.-M. Koo, S. Im, L. Jiang, and K. E. Goodson, "Integrated microchannel cooling for threedimensional electronic circuit architectures," Journal of Heat Transfer, vol. 127, no. 1, pp. 49-58, 2005.

doi: $10.1115 / 1.1839582$

[6] L. Zhang, J.-M. Koo, and L. Jiang, "Measurements and modeling of two-phase flow in microchannels with nearly constant heat flux boundary conditions," IEEE Journal of Microelectromechanical Systems, vol. 11, no. 1, pp. 12-19, 2002.

doi: $10.1109 / 84.982858$

[7] L. Zhang, E.-N. Wang, K. E. Goodson, and T. W. Kenny, "Phase change phenomena in silicon microchannels," International Journal of Heat and Mass Transfer, no. 8, vol. 48, pp. 1572-1582, 2004. doi: 10.1016/j.ijheatmasstransfer.2004.09.048

[8] L. Jiang, M. Wong, and Y. Zohar, "Forced convection boiling in a microchannel heat sink," IEEE Journal of Microelectromechanical Systems, vol. 10, no. 1, pp. 80-87, 2001.

doi: $10.1109 / 84.911095$

[9] W. Zhang, T. Hibiki, and K. Mishima, "Correlation for flow boiling heat transfer at low liquid Reynolds number in small diameter channels," Journal of Heat Transfer, vol. 127, no. 11, pp. 1214-1221, 2005. doi: $10.1115 / 1.2039105$

[10] D. Liu, P.-S. Lee, and S. V. Garimella, "Prediction of the onset of nucleate boiling in microchannel flow," International Journal of Heat and Mass Transfer, vol. 48, no, 25-26, pp. 5134-5149, 2005.

doi: 10.1016/j.ijheatmasstransfer.2005.07.021

[11] S. G. Kandlikar and P. Balasubramanian, "An extension of the flow boiling correlation to transition, laminar, and deep laminar flows in minichannels and microchannels," Heat Transfer Engineering, vol. 25, no. 3, pp. 86-93, 2004. doi: $\underline{10.1080 / 01457630490280425}$

[12] X.-F. Peng, G. P. Peterson, and B. X. Wang, "Flow boiling of binary mixtures in microchanneled plates," International Journal of Heat and Mass Transfer, vol. 39, no. 6, pp. 1257-1264, 1996. doi: 10.1016/0017-9310(95)00204-9

[13] B. E. Haendler, C. L. Sun, and K. L. Pettigrew, "Evaporation of methanol/water mixtures in microchannels," in proceedind of International Mechanical Engineering Congress and Exposition, Washington, DC, USA, Nov. 15-21, 2003, pp. 507-514. doi: 10.1115/IMECE2003-41863

[14] J. R. Taylor, An Introduction to Error Analysis, 2nd ed. Sausalito, CA, USA: University Science Books, 1997.

[15] B. E. Poling, J. M. Prausnitz, and J. P. O'Connell, The Properties of Gases and Liquids, New York, USA: McGraw-Hill, 2001.

[16] S. Ohe, Vapor-Liquid Equilibrium Data. Tokyo, Japan: Kodansha, 1989.

[17] C. L. Yaws, Chemical Properties Handbook: Physical, Thermodynamic, Environmental, Transport, Safety, and Health Related Properties for Organic and Inorganic Chemicals. New York, USA: McGraw-Hill, 1999.

[18] V. P. Carey, Liquid Vapor Phase Change Phenomena: 
An Introduction to the Thermophysics of Vaporization and Condensation Processes in Heat Transfer Equipment, 2nd ed. New York, USA: Taylor \& Francis, 2008.

[19] J. G. Collier and J. R. Thome, Convective Boiling and Condensation, 3rd ed. Oxford, UK: Oxford University Press, 1994.

[20] D. Liu and S. V. Garimella, "Flow boiling heat transfer in microchannels," Journal of Heat Transfer, vol. 129, no. 10, pp. 1321-1332, 2007. doi: $\underline{10.1115 / 1.2754944}$
[21] P. A. Kew and K. Cornwell, "Correlations for the prediction of boiling heat transfer in small-diameter channels," Applied Thermal Engineering, vol. 17, no. 8-10, pp. 705-715, 1997.

doi: $10.1016 /$ S1359-4311(96)00071-3

[22] S. S. Bertsch, E. A. Groll, and S. V. Garimella, "Effects of heat flux, mass flux, vapor quality, and saturation temperature on flow boiling heat transfer in microchannels," International Journal of Multiphase Flow, vol. 35, no. 2, pp. 142-154, 2009. doi: 10.1016/j.ijmultiphaseflow.2008.10.004 